\title{
Complementary and Alternative Medicine Use by the Indigenous Yoruba and Non-Indigenous Hausa People in Ibadan, Nigeria: A Qualitative Comparative Study
}

\author{
Chinyerem C. Nwachukwu ${ }^{1 *}$, Akinola A. Fatiregun ${ }^{2}$, Amaechi C. Nwachukwu', Ayodeji M. \\ Adebayo $^{4}$, Eme T. Owoaje ${ }^{4}$ \\ ${ }^{I}$ Department of Community Medicine, Chukwuemeka Odumegwu Ojukwu University, Awka, Nigeria \\ ${ }^{2}$ World Health Organization, Nigeria Country Office, Ondo State \\ ${ }^{3}$ Department of Surgery, Chukwuemeka Odumegwu Ojukwu University, Awka, Nigeria \\ ${ }^{4}$ Department of Community Medicine, University of Ibadan, Ibadan, Nigeria
}

*Corresponding Author: Chinyerem C. Nwachukwu, Department of Community Medicine, Chukwuemeka Odumegwu Ojukwu University, Awka, Nigeria, Email: chinyeremcynthia@yahoo.com

\begin{abstract}
Background: Many orthodox medicines are based on compounds found in natural herbs. Several home remedies have been used for the treatment of diseases for ages. This study compared Complementary and Alternative Medicine (CAM) use among two ethnic groups.
\end{abstract}

Methods: A qualitative, comparative study among Yoruba and Hausa people resident in Ibadan, Nigeria. Information on type of CAM, indications and other reasons for use, satisfaction and adverse effects experienced were collected using focus group discussions.

Results: Common CAM used included homemade and commercially prepared herbal medicines. There were some similarities in the herbs mentioned by the two ethnic groups like using neem leaves for the treatment of malaria, though different methods of preparation may be described. Other practices included drinking one's early morning urine for the treatment of gonorrhoea, and treating of convulsion by giving the child cow's urine to drink and rubbing cow's feaces on skin. Some CAM were sold by hawkers at affordable prices and may be given for free if the sick person is indigent. The migrant ethnic group, Hausa, reported obtaining some CAM from their place of origin. The main reasons given for CAM use were belief in the practitioner, efficacy, availability and affordability of CAM compared to orthodox medicine.

Conclusion: Many of the herbs mentioned by respondents have been scientifically proven to be beneficial for same and other diseases. Further research should be carried for possible discovery of new drugs. There is also the need to make orthodox health care easily accessible and affordable.

Keywords: Complementary, alternative, traditional, medicine, ethnic, herbs, reasons, disclosure, satisfaction, cost.

Abbreviation: Complementary and Alternative Medicine (CAM)

\section{INTRODUCTION}

Our current medical knowledge has evolved from the cumulative experience of man from primitive to present times. Modern medicine is what it is today because it has drawn richly from the traditional cultures of several people and societies, at different stages [1]. Complementary and alternative medicine (CAM) is a group of diverse medical and health care systems, practices, and products that are not generally considered part of conventional medicine [2].
They are considered as complementary when they are used in conjuction with orthodox or modern medicine, or as alternative medicine when thay are used instead of orthodox medicine.

Alternative medicine has been the fundamental method used by humans to preserve their health and avoid diseases since ancient times. It is also an alternative for those who live far from medical facilities, in places where there are no physicians. Even where there are physicians, 
many people still take the lead in their own health care. Ordinary people provided with clear and simple information can prevent and treat many common health problems in their homes, which can stop diseases early and provide cheaper treatment. It is the belief of many that the art of healing comes from nature, from God, and not only from the physician [3].

Many orthodox medicines are based on compounds found in natural herbs for example quinine, aspirin, digitalis, codeine, to mention but a few. Artemisinin, a plant ingredient used in southern China for centuries to fight malaria, became regarded as the best treatment for the disease after research proved its ability to clear parasites quickly. Garlic has been shown to reduce cardiovascular events by lowering plasma cholesterol, blood pressure and by inhibiting platelet aggregation [4,5]. Extracts of plants and animals from diverse parts of Nigeria have been found to be useful for treating malaria [6,7], epilepsy [8], dementia [9], sickle cell anaemia and bronchial asthma [10].

A wide variety of CAM has been reportedly used in different parts of the world. Some of these are indigenous in the places where they are used while others have been acquired from other culture. CAM is included in the United States 2007 National Health Insurance Scheme (NHIS). These include acupuncture, ayurveda, biofeedback, chelation therapy, chiropractic or osteopathic manipulation, deep breathing exercises, diet-based therapies (such as atkins diet, ornish diet, pritikin diet, south beach diet, macrobiotic diet, vegetarian diet and zone diet), hypnosis, massage, energy healing therapy/ Reiki, guided imagery, homeopathic treatment, meditation and movement therapies (such as Alexander technique, Feldenkreis, Pilates and Trager psychophysical integration). Others are natural products (non-vitamin and non-mineral, such as herbs and other products from plants, enzymes, fish oil/omega 3, flaxseed, gingseng, glucosamine, echinacea, ginkgo and garlic supplements etc.), naturopathy, progressive relaxation, Qi gong, Tai chi, traditional healers (such as botanica, curandero, espiritista, hierbero or yerbera, native American healer/ medicine man, shaman, sobador) and yoga. Other forms of CAM that are not included in America NHIS are hot stone therapy, acupressure, chakra awakening, aromatherapy and prayer [2].
CAM commonly used in Nigeria include natural products (such as herbal drugs, medicinal tea, aloe vera, Chinese medicine, animal extract e.g. python fat, ginger, garlic, bitter kola, bitter leaf, lemongrass), 'burantashi' (an aphrodisiac), ginseng, St. John's wort, Tasly ${ }^{\circledR}$, Noni ${ }^{\circledR}$, Forever Living Product ${ }^{\circledR}$, GNLD $^{\circledR}$ products, Jobelyn ${ }^{\circledR}$ products, $\quad$ Tianshi $^{\circledR}$ products, $\quad$ Yem-kem $^{\circledR}$ products. ${ }^{420-22}$ In addition, there are religious practices such as the use of blessed/anointed water and oil, faith healing, scarification, wearing of charms, ritual sacrifice and incantations. Other practices include the use of magnetic water, black stone, black soap bath, urine therapy, massages, and traditional bone setters $[5,11,12]$.

Herbal products were the most commonly used CAM type among patients with essential hypertension attending a tertiary hypertension clinic in Lagos, Nigeria. The common herbal product used by the patients were garlic (69.3\%), native herbs (25\%), ginger (23.9\%), bitter leaf (Vernonia amygdalina) (9.1\%), and aloe vera $(4.5 \%)$. Also $2.5 \%$ of them used spiritual therapy [13]. Varied combinations of herbs in combination with different types of fruits and other substances are said to be used in the treatment of malaria by respondents in Lagos State, Nigeria. The main ones of which are Azardiracha indica and pineapple [14]. Thirty eight percent of the patients in a secondary health facility in Ibadan, Nigeria revealed that they use alcoholic beverages for extracting plant materials themselves [15].

Studies have found that most Americans use CAM as an adjunct to, rather than a substitute for, conventional medical care [16-18]. A community-based study done in America showed that herbals/supplements were taken by $14 \%$ of the general population.

Blood-letting for medicinal purposes has been reported to be common in sub-Sarahan Africa, especially in rural areas. The practitioners use sharp instruments such as razor blades or knives, to make cuts deep enough to allow blood to flow freely. They then take a mixture of ashes made from leaves and rub it into the wound, potentially exposing themselves to the patients' blood. In eastern Zaire the cuts are made over the affected organ, for example, the forehead for headache, the abdomen for stomach pains, and the joints for arthritis. It was estimated that most people among the Lese ethnic group have bloodletting ('chanja') performed at least five 
times per year from infancy onward. Many people have more than 100 'chanjas' performed yearly [19].

A report from World Health Organisation (WHO) showed that in many countries, 70\% $80 \%$ of the population depend on traditional medicine for primary health care or used some form of CAM [20]. According to the WHO, herbal medicines are the first line of treatment for $60 \%$ of children with high fever due to malaria in Nigeria, Ghana, Mali and Zambia [21]. A hospital-based study in Aba, Nigeria showed that the most common form of medical intervention at home before the visit was the use of herbal remedies, $47.3 \%$; scarifications/bloodletting procedures, $42.5 \%$; and application of paste on the anterior fontanelle, $1.2 \%$ [22].

A study in Ibadan, Nigeria on the knowledge and home management practices regarding malaria fever of mothers and care givers of under five children in a clinic revealed that $20.9 \%$ of the respondents believed that malaria could be prevented by the use of traditional herbs 'agbo'. The elders and friends were the major sources of information. "Agbo", had been used by $25.5 \%$ mothers before presenting at the clinic [23].

The practice of Nigerian traditional healers of Yoruba ethnicity regarding the care of neonates revealed that $64.2 \%$ of the 165 herbalists studied also practices midwifery. Some herbalists $(20.7 \%)$ use herbal medicine to dress the umbilical stump some of which may contain bird droppings, ashes, alligator pepper and gun powder. The mothers were sometimes advised to give the baby protective charms and an 'ayewo' should be made into the child's horoscope, especially to determine whether the child should be given hot or cold water to drink. The methods for the treatment of neonatal jaundice among the group studied included concoction ('agbo tutu', 'agbo-ponju'), 69\%; herbal medicines ('agunmu', soup, topical applications), 16\%; and black soap, 16\% [24]. Herbal tea was reported to have been given to about half $(47 \%)$ of neonates in Igbo-Ora, Oyo State, Nigeria during their first week of life and 97\% had taken herbs by the fourth month [11].

Another study of 127 traditional healers in South-Western Nigeria showed that $72 \%$ of them treat malaria in children with boiled herbs ('agbo'), 14\% with ground herbs ('agunmu'), and 3\% with incisions and scarifications [25]. Another study involving 514 traditional healers, herb sellers, elders and mothers in rural and urban LGAs in Oyo State showed that methods of fever prevention were mainly with the use of herbal decoctions, powdered herbs, orthodox medications and maintenance of proper hygiene. Of a total of 112 different herbal remedies used in the treatment of the febrile illnesses compiled from the study, 25 recipes are presented. Recipes consisted of 2-7 ingredients. Boiling in water or alcohol was the most common method used in the preparation of the remedies. The four most frequently mentioned plants for fevers were Azadirachta indica (87.5\%), Mangifera indica (75.0\%), Morinda lucida (68.8\%) and Citrus medica (68.8\%) [26].

The most common reason for using CAM as reported by homeless youth attending a free clinic in America was because it was natural and organic $(43.9 \%)$. Other reasons included low cost (28\%), perceived efficacy (26.1\%), negative experiences with physicians $(24.2 \%)$, friends use CAM and recommended it (20\%), and pervasive mistrust of physicians (19\%) [27]. Family practice patients in America gave similar reason for CAM use [28].

Pressure of elders, family members, friends and neighbours was a common reason why people used alternative medicine [29]. There is also the cultural beliefs that illnesses have a 'spiritual' origin and people are interested in finding the root cause of their problems and therefore consult with alternative practitioners [30].

Although alternative medicines may have health benefits, adverse reactions have been reported with a number of them. Worthy of note is the administration of cow's urine concoction to convulsing children by the Yoruba-speaking people of Nigeria which is usually complicated by severe poisoning [31]. A study of inpatients in a secondary health facility in Ibadan found that $9 \%$ had experienced adverse effects with the use of herbs, with $2 \%$ experiencing adverse reactions on co-administration with prescribed drugs [15]. Another study suggests that a Nigerian herbal supplement may have toxic effect on the spleen, pancreas and heart of male albino rat [32].

A hospital-based study involving 360 mothers of children under five years of age in Barkin Ladi, a rural Local Government Area (LGA) in Plateau State, Nigeria showed that the major factors causing non-attendance at the available health services in the LGA included the high costs of drugs (29\%) and service charges (19\%), 
easy access to traditional healers (39\%) and difficulty in getting transport to a health facility (30\%) [33].

For respondents in a community-based study in Lagos State, perceived efficacy of herbs in treating malaria episodes featured as the major reason for their use as claimed by the majority $(>50 \%)$ of the respondents in each of the ethnic groups studied, while cost consideration was the next most important factor. Other factors mentioned included the absence of side effect in herbal use and to avoid the itching side effect and ineffectiveness of chloroquine and some other anti-malarials [14].

The majority of mothers from eighty villages in Nigeria, whose children were suffering from covert or overt malnutrition, had no idea as to the cause and prevention of protein energy malnutrition (PEM). According to the respondents, the means of preventing the disease included the use of charms, scarification, herbs, and prayer [34].

Many respondents in a Lagos State study, across the ethnic groups, had no idea of the constituents of the herbal remedies they use for treating their malaria episodes since they buy these from traditional herbalists. A majority of respondents of different ethnicity said that they use the same herbs for the treatment and prevention of malaria and experience great improvement after use [Hausas (90\%), Igbos $(83 \%)$, Yorubas $(77 \%)$ and the other ethnic groups (88\%)]. There is usually no specific dose or dose regimen, however, a high proportion in all the ethnic groups use herbal preparation thrice a day and a few of the respondents take unspecified measures at arbitrary intervals [14].

Sources of information about CAM included the media: television, radio and newspaper advertisements (13\%); CAM practitioners (5\%); churches (2\%); open market advertisements (2\%); and hospital staff (1\%) [29]. Respondents in a community based study in Australia obtained information on CAM from CAM practitioners. The internet and health food shops served as the least useful source of information [35]. Fifty seven percent of CAM providers reported attending educational programmes on dietary supplement, while the use of supplements by patients was most influenced by advertisements (40\%) and friends (40\%) [36]. Other studies have shown that information on CAM were obtained from the internet and other data bases [37-39] as well as from staff at retail herb stores [40, 41]. Only 3\% of respondents in an America study reported that their primary source of information was a doctor, nurse, or pharmacist [40]. Other studies have also reported that friend, family and the media were important sources of information [42].

\section{Materials ANd Methods}

\subsection{Study Area}

The study area was Ibadan North Local Government Area in Ibadan, the capital of Oyo State, South-West zone of Nigeria. The Yorubas are the indigenous people. Two wards within the study area, Sabo, whose inhabitants are predominantly of Hausa ethnicity, and Inalende, whose inhabitants are predominantly of Yoruba ethnicity were purposively selected and used for the study. The majority of these inhabitants are petty traders and artisans. A great majority of the inhabitants have no formal education and belong to the low socio-economic class. Sabo and Inalende areas of Ibadan are unplanned urban slum areas of Ibadan characterised by limited access to pipe borne water, irregular supply of electricity and overcrowding. A private clinic was located in Inalende ward. A private clinic and a Primary Health Care centre were located within Sabo ward.

\subsection{Study Population}

Participants were at least 18 years old.

\subsection{Study Design}

Qualitative data collection employing Focus Group Discussions (FGDs). Eight groups were constituted taking into consideration ethnicity, sex and age to ensure that the members of each group were comfortable to contribute in the midst of their peers.

A total of eight FGDs were conducted:

- FGD1 - Yoruba younger adult males, aged $18-34$ years (YYM).

- FGD2 - Yoruba older males, aged 35 years and above (YOM).

- FGD3 - Yoruba younger adult females, aged $18-34$ years (YYF).

- FGD4 - Yoruba older females, aged 35 years and above (YOF).

- FGD5 - Hausa younger adult males, aged 18 - 34 years (HYM).

- FGD6 - Hausa older males, aged 35 years and above (HOM). 
- FGD7 - Hausa younger adult females, aged $18-34$ years (HYF).

- FGD8 - Hausa older females, aged 35 years and above (HOF).

Each focus group was made up of $6-10$ persons excluding a moderator, a recorder and an observer. The moderator facilitated the discussion using the FGD guide, and ensured participation of every member of the group. The recorder recorded the discussion with a tape recorder as well as taking notes on paper, while the observer took note of the non-verbal expressions of participants. The FGDs took place in the premises of the central mosque in Sabo and in an open space in front of a shop in Inalende.

\subsection{Ethical Consideration}

Informed consent was obtained from the respondents and participation was voluntary. Approval for the study was given by Oyo State Ethical Review Committee.

\subsection{Definition of Study Variables}

- Complementary and alternative medicine (CAM) is a group of diverse medical and health care systems, practices, and products that are not generally considered part of conventional medicine, whether they are indigenous or foreign to the culture. ${ }^{24}$

- 'Pile' or 'jedi jedi' (as used by the respondents) is a poorly defined symptom complex of back pain, constipation, abdominal pain, passage of watery/mucoid stool, problems with urination and defecation, sexual dysfunction, etc.

- Urine therapy refers to the practice of drinking one's own urine.

- It should be noted that the diseases mentioned by the respondents are not necessarily confirmed in the laboratory but are sometimes based on symptoms.

- Efforts has been made to identify the botanical names or English names of the mentioned herbs and items.

\subsection{Data Analysis}

Data from the focus group discussions were transcribed and analyzed manually under different themes. They are presented in prose and boxes in a comparative format. A diagram was used to summarize the findings from the FGDs.

\section{Results}

\subsection{Types of CAM and Indications for Use}

The respondents mentioned different types of alternative medicines and mixtures that serve as remedies for different ailments. Most of the medicines were home made from readily available ingredients. Some similarities exist in the remedies reported by different groups and ethnicity for the treatment of febrile illness. Both ethnic groups mentioned the use of 'dongoyaro' (neem) leaves or tree bark, among other herbs, for the treatment of malaria, although different methods of preparations were described.

The remedies and herbal preparations mentioned by the respondents have been presented below.

\section{- Malaria}

\section{Yoruba}

"the bark of dongoyaro tree should be soaked in water or seven up ${ }^{\circledR}$ (carbonated soft drink) and 2-3 spoonfuls taken daily"

"drink \& bath or steam with water in which 'akintola' (Chromolaena odorata) leaves, 'oruwo' (Morinda lucida/Nigeria's chewing stick) leaves, lemon grass or male pawpaw leaves has been boiled"

"boil a mixture of lime leaves, onion leaves and locust bean (Parkia biglobosa) and drink the water"

"drink a mixture of newly laid egg plus lime plus 'alabukun' medicine (a brand of aspirin/caffeine powder)"

"boil lime, bark of mango tree and lemon grass in stale water decanted from pap (a porridge food made from ground maize and other grain, the raw form is preserved by pouring water over it while it settles at the bottom when it is left undisturbed) and drink the liquid"

"boil lipton (tea bag) and lime in water decanted from pap and drink the liquid"

'grind leaves of 'ewe rinrin' (Peperomia pellucida) mix with palm oil or shea butter and rub on the body"

"cut in pieces unripe pineapple, grape fruit, cotton seed, boil and drink extract"

\section{Hausa}

"'dogonyaro'/'darbejiya' (Hausa words for same neem tree) leaves should be boiled in 
water and the water should be drunk or used for bathing"

"drink or bath with water in which 'darbejiya' (neem), mango and guava leaves have been boiled or add the dried powdered leaves to pap, tea, soup or stew. The sickness will be passed out in the urine"

"drink 'dankano' herbs after boiling in water"

“'nanapa' should be dried \& ground into powder and added to food"

"drink or bath with water after boiling 'dogonyaro' leaves”

"'madachi' bark (bitter herbs/Khaya senegalensis/African mahogany) is boiled and water drunk"

"boil 'sabara' herbs (Guiera senegalensis) and drink water (drinking 'sabara' also cleans the breast and removes sicknesses from breast milk immediately after delivery instead of discarding the 1st milk)".

\section{- Hypertension}

\section{Yoruba}

"drink bitter leaves (Vernonia amygdalina) extract"

"boil leaves of 'olodundunju and lime and drink the liquid"

"eat raw onion leaves"

\section{Hausa}

"drink 'sabara' (Guiera senegalensis) herbs"

"dry and pound moninger leaves, add the powder to food"

\section{- Depressed Fontanelle}

Yoruba

"apply ground bark of tree mixed with black soap over fontanelle"

\section{'Pile'/'jedijedi'}

\section{Yoruba}

"'Iyere' (African black pepper) and 'Kafura' (Kafura pelebe/camphor)

\section{Hausa}

“'dankano' herbs”

" "dauri' herbs"

“'madachi' (bitter roots/bitter herbs/Khaya senegalensis/African mahogany)" "alligator pepper and 'kafura', soak in water and drink"

\section{- Gonorrhea}

\section{Yoruba}

"eat cooked 'bara' melon (bitter melon/Citrullus Colocynthis) with palm kernel oil (YYM, FGD1)

"drink early morning urine" (YYM, FGD1)

“'bara'melon (bitter melon/Citrullus Colocynthis) and potash soaked in lime, take 2 spoonfuls daily" (YOM, FGD2)

\section{- Cough and Catarrh}

\section{Yoruba}

"trebor ${ }^{\circledR}$ (mint sweet) plus little alum dissolved in water plus bitter kola taken in small quantities with a spoon"

"lick hot ash plus sugar plus lime plus palm oil" "soak sliced riverine banana in water decanted from pap and drink the water"

\section{Hausa}

"mix honey and lime, take 1-2 spoonfuls or $2.5 \mathrm{mls}$ for a baby"

"soak 'tafarnuwa' (garlic) and red potash in water and drink"

\section{- Childhood Convulsion}

Yoruba

"rub cow's faeces on skin and give a drink of cow's urine"

"soak sliced riverine banana in water decanted from pap and drink the water"

"grind leaves of 'ewe rinrin' (Peperomia pellucida) mix with palm oil or shea butter rubbed on the body"

\section{- Typhoid Fever}

Yoruba

"boil bark of pear tree, unripe pineapple and lime in water decanted from pap \& drank"

\section{- Anaemia}

Yoruba

"mix extract of 'ogbo' leaves with a tin of evaporated milk and a cube of sugar"

“'Poro' (poroporo oka baba/dried sorghum or guniea corn leaves) is cooked with potash and water is drunk" 


\section{- Infection}

\section{Yoruba}

"eat raw onion leaves"

"drink extract of bitter leaf mixed with gin/schnapp"

"soak riverine banana and onion leaves in water for three days and give to a baby to drink"

\section{- Tinea Capitis/Ring Worm/ Skin Infection}

\section{Yoruba}

"'enu opiri' leaves (Euphorbia laterifolia), onions, small local pepper soaked in gin and drink"

"sulfur mixed with other things and applied to the skin"

"mix gun powder and palm kernel oil and rub on skin"

"engine oil mixed with camphor and applied on skin"

"grind red stone ground into powder, mix with palm kernel oil and rub unto the skin"

\section{Hausa}

"shave hair, apply some herbs mixed with black soap and wash after some minutes"

"rub 'sabara' herbs (Guiera senegalensis) on skin"

\section{- Asthma}

\section{Yoruba}

“'arafuru', onion leaves and 'oganho' bark soaked in water, drink water"

\section{- Yellow Fever}

\section{Yoruba}

"boil bark of mango tree and drink water"

\section{- Sickle Cell Crisis}

Yoruba

"drink 'dogoyaro' leave extract"

\section{- Contraception}

\section{Yoruba}

"wearing local rings during sexual intercourse"

"scarification"

"avoid eating egg"

- Demonic Powers
Yoruba

"eating whole egg destroys demonic power"

\section{- Tiredness in Pregnancy}

Yoruba

"add ground snail shell to food"

\section{- Wound Healing}

\section{Yoruba}

"apply honey to the wound"

\section{- Toothache}

\section{Hausa}

"make a paste of powdered 'bugaruwa' (Acacia nilotica) herb and apply it to affected tooth"

'soak 'kuka' (baobab leaf) in hot water \& use to gargle"

"soak 'hanu'/'ararabi' (Boswellia odorata Hutch) in water and use it to gargle"

\section{- Measles}

Yoruba

"cow's urine is given to the child to drink"

\section{Hausa}

"white onions is pounded and the juice given to the child to drink and is also rubbed on the skin"

"rub cow faeces on skin \& give child a little cow urine to drink"

\section{- Abdominal Pain}

\section{Yoruba}

“'Ayu' and onion leaves soaked in water for 3 days and drink liquid"

"'Caphra' and 'kamfari'”,

\section{Hausa}

"'sayan nanapa' boiled in water \& drank the liquid"

"soak the root of a bitter herb (madachi) in water and drink"

"mix herbs with red potash"

"'dauri' herbs, 'caffira' herbs, 'kananfari' herbs"

\section{- All Diseases}

Yoruba

"pray into water and drink it" 


\section{Hausa}

"use 'madachi' (bitter roots/bitter herbs/Khaya senegalensis/African mahogany)"

\subsection{Reasons for Complementary and Alternative Medicine (CAM) use}

Many participants said that alternative medicine is cheap and usually much cheaper than orthodox health care. Other reasons were efficacy and accessibility and short treatment duration for traditional medicine of 2-3 days compared to 2-3 weeks of treatment or sometimes for life for orthodox medicine HOF, FGD8.
An incidence was recounted by a Hausa younger male participant. He had a similar illness ('measles') as another person. The order person was taken to a hospital, he was treated locally. A sheep was slaughtered, the abdomen was opened and the warm content was emptied on him. He also drank the urine for one week. He recovered within 2 weeks while the person that visited the hospital became well after over a month HYM, FGD5.

The Hausa older men and women emphasized poverty as a major reason for resorting to alternative medicine. Some of their responses are shown in Table 1.

Table1: Reasons for CAM use

\begin{tabular}{|c|c|}
\hline Yoruba & Hausa \\
\hline $\begin{array}{l}\text { "Alternative medicine is curative } \\
\text { while orthodox medicine is for } \\
\text { emergency". YYM, FGD1 } \\
\text { "It cures serious problems } \\
\text { including cancer". YYM FGD1 } \\
\text { "It is also readily available and } \\
\text { some can be prepared at home } \\
\text { with readily available materials. } \\
\text { There is also no need of waiting } \\
\text { for hours to see a doctor". YYF, } \\
\text { FGD3 } \\
\text { 'It ensures total cure unlike } \\
\text { orthodox medicine that gives } \\
\text { temporary relief. When you take } \\
\text { herbal concoction, it would not } \\
\text { only cure it' pile' but it would } \\
\text { also remove it and you will pass it } \\
\text { out in your faeces that means that } \\
\text { the problem has been solved'. } \\
\text { YOM, FGD2 } \\
\text { "Alternative medicine will help } \\
\text { the patient to urinate every form } \\
\text { of malaria, but orthodox medicine } \\
\text { will only solve the acute } \\
\text { problem". YOF, FGD4 }\end{array}$ & $\begin{array}{l}\text { "In most cases, our traditional medicine works better than hospital } \\
\text { medicine because when you drink it, it works for a longer period before } \\
\text { one will need to take it again, unlike hospital medicine that only } \\
\text { suppresses the sickness". HYM, FGD5 } \\
\text { "Traditional medicines are 100\% effective". HOF, FGD8 } \\
\text { "Traditional medicines are more beneficial than orthodox medicines. } \\
\text { Before we use orthodox medicine thrice, we would have used } \\
\text { traditional medicine seven times". HYM, FGD5 } \\
\text { "This local medicine (madaci or bitter herbs) is working for us the } \\
\text { masses who don't have money to go to the hospital because the person } \\
\text { will just die like that cheaply, but when one has this traditional } \\
\text { medicine, you'll just take it and you'll be okay'. HOM, FGD6 } \\
\text { "Sincerely speaking, the masses of this country Nigeria are not } \\
\text { receiving care from those in authority. For instance, those living in the } \\
\text { rural areas, some are sick, no hospital there, no drugs and no health } \\
\text { personnel around. In this situation, the people will be forced to take } \\
\text { herbal medicine". HOM, FGD6 } \\
\text { "The poor masses cannot afford to pay the huge amount of money that } \\
\text { hospitals ask for as deposit before they can be attended to and after } \\
\text { that, you pay for drug deposit, bed, meals, etc. Bed fee per night is } \\
\text { around } 1 \text { l,500 (\$4)". HOM, FGD6 } \\
\text { It is not fair for doctors and nurses to go on strike. A lot of lives are at } \\
\text { stake and people are in pain. HOF, FGD8 }\end{array}$ \\
\hline
\end{tabular}

\subsection{Places where CAM can be Obtained}

Hausa FGD participants said that they buy alternative medicines in their locality (Sabo), 'you don't have to go searching for them, right where you are sitted, they hawk around with different kinds of traditional medicine'. Some types are sent to them from the northern part of the country, which is their place of origin. The traditional barbers called 'wanzamai' also have a type of alternative medicine.

\subsection{Cost of CAM}

Some alternative medicines are home remedies which can be prepared with locally available ingredients. Some leaves cost only $\$ 10$ (\$0.03), others cost as little as \$40 to \$50 (\$0.12 $\$ 0.15$ ). Hausa respondents said that some CAM can be given for free if the sick person does not have the money to pay. The recipient of such favour will be asked to recommend the medicine to other people if it was found to be effective. Also, other CAM can be purchased for as much as $\$ 500$ to $\$ 1,000$ ( $\$ 1.30-\$ 2.60)$.

\subsection{Source of information on CAM}

Participants reported that they obtained information on CAM from grandparents, parents, friends and open market advertisement/ promotion by drug sellers. Young Yoruba male participants reported that 'from hospitals, they do direct people to use native medicines'. Other 
sources of information included the radio, television and by word of mouth from those who have benefitted from them in the past.

\subsection{Disclosure of CAM use to doctors}

Majority of the participants objected to telling doctors that they use alternative medicines. Their responses are displayed in Table 2.

Table2: Views regarding disclosure of CAM use to doctors

\begin{tabular}{|c|c|}
\hline Yoruba & Hausa \\
\hline $\begin{array}{l}\text { "They (doctors) don't like it'. 'They are } \\
\text { against it, we don't know why". YYM, } \\
\text { FGD1 } \\
\text { "No, it is not necessary to tell them". } \\
\text { YOM, FGD2 } \\
\text { "There is no need of telling a doctor if } \\
\text { you really love yourself". YOF, FGD4 }\end{array}$ & $\begin{array}{l}\text { "The doctors will find another sickness in you and say that it } \\
\text { was caused by the traditional medicine that you took and it will } \\
\text { cost you more money". HYM, FGD5 } \\
\text { 'Doctors do not want to hear anything about herbs. It is not fair } \\
\text { for doctors to be criticizing traditional medicine when orthodox } \\
\text { medicines are traditional medicine that have been developed and } \\
\text { modified, improved and packaged in capsules, tablets and } \\
\text { liquid". HOM, FGD6 } \\
\text { "It is necessary for patients to tell their doctors about the } \\
\text { medicines that they are using so that they can be advised to } \\
\text { discontinue if the medicines are not effective". HOM, FGD6 } \\
\text { "Doctor/nurses get upset and start scolding you. They try to } \\
\text { poison our mind against alternative medicine which is not } \\
\text { supposed to be so. They should understand that life is in phases. } \\
\text { Some years back only few people visit hospitals. But things are } \\
\text { changing fast". HOF, FGD8 }\end{array}$ \\
\hline
\end{tabular}

\subsection{Adverse effects from CAM use}

Participants reported some cases of adverse effects they had witnesses and also gave their

\begin{tabular}{|c|c|}
\hline Yoruba & Hausa \\
\hline $\begin{array}{l}\text { "Adverse effect would depend on your blood group". } \\
\text { YYM, FGD1 } \\
\text { "Too much of using it (CAM) may lead to other } \\
\text { problems". YYM, FGD1 } \\
\text { "Some are not hygienically good" (A story was narrated } \\
\text { of how a child was given a local anticonvulsant filled } \\
\text { with maggot). YOM, FGD2 } \\
\text { "A child was given contaminated herbal tea and he } \\
\text { almost died until the stomach was washed in UCH". } \\
\text { YOM, FGD2. } \\
\text { "There is usually no side effect except when it is not used } \\
\text { as directed, for example using herbs on empty stomach. } \\
\text { Also appropriate dosage is not available". YOM, } \\
\text { FGD2. } \\
\text { "Each individual should know what their body can } \\
\text { tolerate and use same". YOF, FGD4 } \\
\text { "Some people experience vomiting, diarrhoea, excessive } \\
\text { bleeding and swelling of the vagina and some alternative } \\
\text { medicines users may still have to go and see a doctor". } \\
\text { "YYF, FGD3 } \\
\text { "Traditional medicine is not usually given to babies until } \\
\text { they are } 6 \text { months old". YOM, FGD2 } \\
\text { "Some tradition medicines can affect one's kidneys and } \\
\text { are also dangerous for pregnant women and their } \\
\text { unborn babies". YYF, FGD3 }\end{array}$ & $\begin{array}{l}\text { "There can be adverse reactions with both } \\
\text { orthodox and traditional medicines if Allah has } \\
\text { destined that it would happen". HOM, FGD6 } \\
\text { "Adverse reactions following traditional } \\
\text { medicine use is very minimal and mild. No } \\
\text { negative results have been seen from the } \\
\text { medications administered by the traditional } \\
\text { barbers, whereas, there are cases of paralysis } \\
\text { among children in their locality which resulted } \\
\text { from injections given in hospitals". HOM, } \\
\text { FGD6 } \\
\text { "Powdered herbs should not be given to babies } \\
\text { because their systems cannot absorb them and } \\
\text { only very small quantities of liquid forms of } \\
\text { herbs should be given". HYM, FGD5 } \\
\text { "Traditional medicine should be given from } \\
\text { birth". HOM, FGD6 } \\
\text { "Children should only be given herbs from the } \\
\text { age of one". HOF, FGD8 } \\
\text { "I started giving my child herbal concoction } \\
\text { after } 2 \text { days of birth". HYF, FGD7 }\end{array}$ \\
\hline gds & 1. \\
\hline
\end{tabular}

The factors that promote CAM use were identified from the responses of FGD 


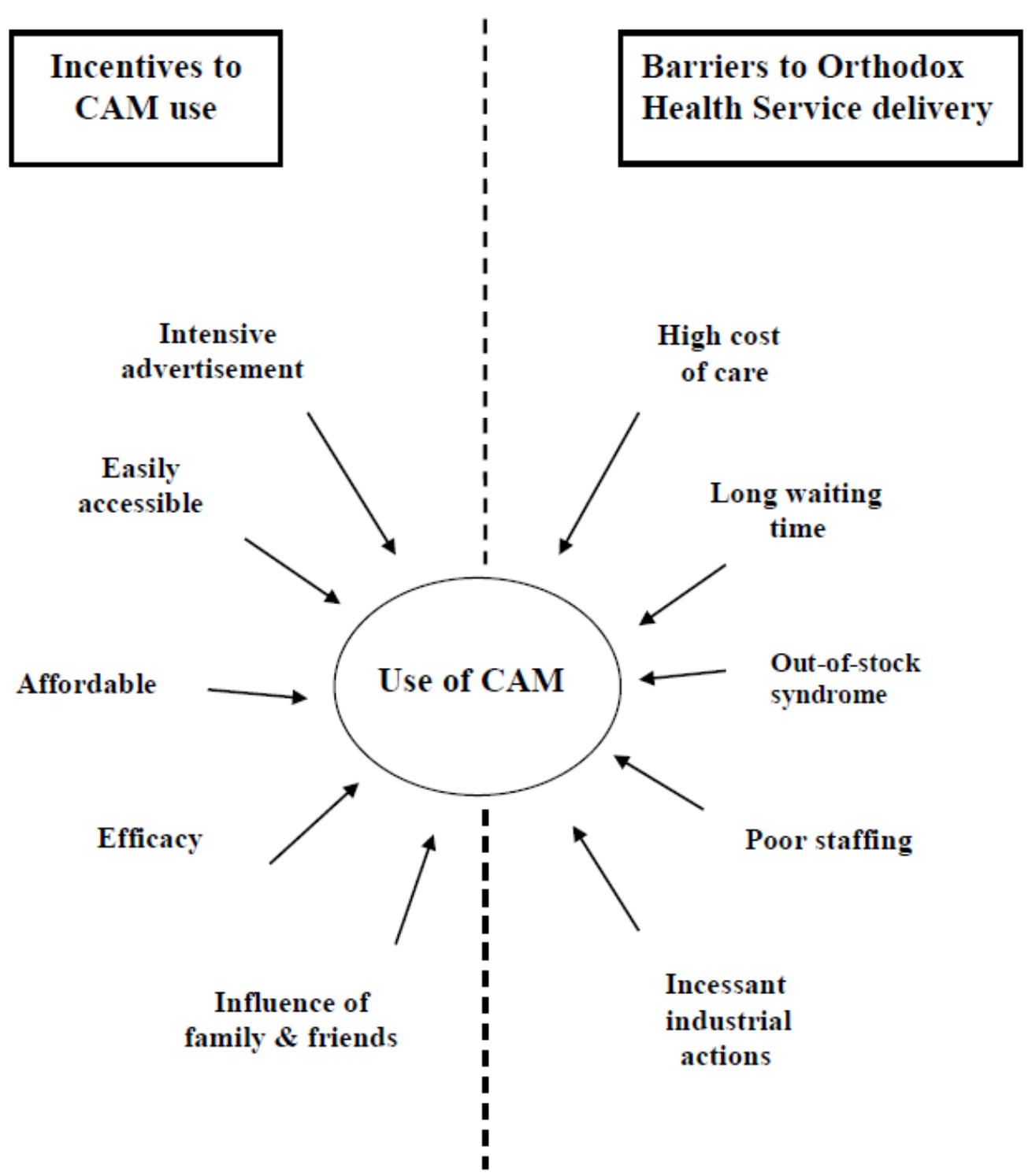

Figure1: Factors promoting CAM use identified from FGDs

\section{DISCUSSION}

The most commonly used CAM by respondents in this study was found to be herbal medicines. Herbal treatments were similarly reported by the WHO as the most popular form of traditional medicine, and are increasingly lucrative in the international marketplace [20]. This was similar to the findings in Lagos state where many Yorubas and Hausas respondents used herbs in treating malaria [14].

Regarding the treatment of fever, reports from the WHO showed that herbal medicine was the first line of treatment for children with febrile conditions in Nigeria and some other African countries [21] and this is similar to the findings of this study where Yoruba and Hausa respondents used herbs for the treatment of fever in their children.
Herbal products were also reported to be the most frequently used CAM in children with chronic conditions in Lagos state [29]. A study in Igbo-Ora found that about half of neonates were given herbal tea during their first week of life [11]. This finding agreed with our study as the respondents reported administering herbal preparations to their children before one month of age.

While the American respondents used CAM as an adjunct to, rather than a substitute for orthodox medical care [16-18], this study found out that many used it as alternative to orthodox medicine.

The commonest health conditions for which respondents in this study used CAM were febrile conditions, 'pile'/'jedi jedi', gastrointestinal conditions and the desire to 
promote health. This is similar to findings in Nepal where abdominal pain, fever and diarrhoea were the commonest illness for which respondents used CAM [43]. On the contrary, American adults were most likely to use CAM for musculoskeletal problems such as back pain, neck pain, joint pain as well as for colds and anxiety/stress [2]. This is expected because the burden of communicable diseases in developing countries is still high unlike in developed countries.

The main reason given for using herbs by respondents in Lagos state is its efficacy in treating malaria [14]. Also, efficacy was the main reason given by family practice patients in America [13]. This is similar to findings of this study as efficacy was one of the reasons given, as well as availability and claims of the CAM practitioner. These reasons and others like high cost of hospital care, non-availability of drugs in public hospitals and health centres, influence of family and friends, absence of side effect, and CAM's ability to cure diseases of spiritual origin were found by other studies in Lagos state [13], Plateau state [33], Nepal [43] and America [27]. However, another study in America found that the commonest reason for CAM use was because it was natural and organic [13].

Many of our respondents were satisfied with CAM use. A study among American youth reported substantial benefits from CAM use [27] which is similar to the result of this study.

Respondents' sources of information on CAM are similar to results of other studies. These sources of information are the mass media, CAM practitioners, family, friends and hospital staff which were reported by studies done in Lagos [29] and America [36]. On the contrary, other studies in Exeter (United Kingdom), Australia and America reported that the internet and other data bases were important sources of information on CAM [37-39]. This is not surprising since the literacy rate in these developed countries is high and these sources of information are available to the masses, whereas this study was conducted in an urban slum area with lower literacy level and socio-economic class. A few respondents (1.9\%) obtained information on CAM from hospital staff as similarly reported by $3 \%$ of American respondents [40]. Similarly, our respondents reported being advised by hospital staff to use herbal medicine.

\section{REFERENCES}

[1] Umaru FA. Modern and traditional medicine, conflicts and reconciliation. 1st ed. Ibadan: Spectrum books limited; 2006.

[2] National Centre for Complementary and Alternative Medicine. The use of Complementary and Alternative Medicine in the United States 2007.

[3] Oumeish Y. The philosophical, cultural, and historical aspects of complementary, alternative, unconventional and integrative medicine in the old world. Arch dermatol. 1998;134(1):1373-86.

[4] Traditional medical care in Nigeria [database on the Internet] [cited November 20, 2009]. Available from: http://www.onlinenigeria.com/ links/LinksReadPrint.asp?blurb=574.

[5] Ajaiyeoba E, Falade CO, Fawole OI, Akinboye DO, Gbotosho GO, et al. Efficacy of herbal remedies used by herbalists in Oyo State Nigeria for treatment of Plasmodium falciparum infections - a survey and an observation. Afr J Med Med Sci. 2004;33:1159.

[6] Tor-anyiin TA, Sha'atto R, Oluma H. Ethnobotanical survey of anti-malarial medicinal plants among the Tiv people of Nigeria. J Herbs Spices Medicinal Plants. 2003;10:61-74.

[7] Etkin N. A Hausa herbal pharmacopoeia: biomedical evaluation of commonly used plant medicines. J Ethnopharmacol. 1981;4:75-98.

[8] Gill L. Ethnomedical uses of plants in Nigeria. Benin City: University of Benin Press; 1992.

[9] Abascal K, Yarnell E. Alzeheimer's disease: part 1- biology and botanicals. Alternat Complement Ther. 2004;10:18-21.

[10] Edeoga H, Gomina A. Nutritional values of some non-conventional leafy vegetables of Nigeria. J Econ Taxon Bot. 2000;24:7-13.

[11] Nwankwo BO, Brieger WR. Exclusive Breastfeeding is Undermined by Use of Other Liquids in Rural Southwestern Nigeria. Journal of Tropical Pediatrics. 2002;48(2):109-12.

[12] Abubakar SB, Matthew J. Amputation and disability following snake bite in Nigeria. Tropical Doctor. 2010;40:114-6.

[13] Amira OC, Okubadejo NU. Frequency of complementary and alternative medicine utilization in hypertensive patients attending an urban tertiary care centre in Nigeria. BMC Complement Altern Med. 2007;7(30).

[14] Idowu E, Mafe MA, Otubanjo OA, Adeneye AK. Herbal remedy in the treatment of malaria: cross sectional survey of residents of Lagos State, Nigeria. Afr J Med Med Sci. 2006 June; 35(2):149-53. 
[15] Fakeye T, Tijani A, Adebisi O. A survey of the use of herbs among patients attending secondary-level health care facilities in southwestern Nigeria. J Herb Pharmacother. 2007;7(3-4):213-27.

[16] Kronenberg F, Cushman LF, Wade CM, et al. Race/ethnicity and women's use of complementary and alternative medicine in the United States: Results of a national survey. Am J Public Health. 2006;96:1236-42.

[17] Druss B, Rosenheck RA. Association between use of unconventional therapies and conventional medical services. JAMA. 1999; 282:651-6.

[18] Eisenberg DM, Kessler RC, Foster C, Frances E. Norlock FE, Calkins DR, Delbanco TL. Unconventional Medicine in the United States - Prevalence, Costs, and Patterns of Use. N Engl J Med. 1993;328:246-52.

[19] Philip T. Use of traditional medicine and globalized complementary and alternative medicine among low-income cancer service users in Brazil. Integrative Cancer Therapies. 2006;5(3):232-5.

[20] World Health Organization. Traditional Medicine 2008 Contract No.: Fact sheet No. 134.

[21] World Health Organization/UNICEF. The Africa Malaria Report 2003.

[22] Chapp-Jumbo A. Traditional practices affecting child health: a sub-saharan African experience. Pediatrics. 2008;121:S97.

[23] Fawole OI, Onadeko MO. Knowledge and home management of malaria fever by mothers and care givers of under five children. West Afr J Med. 2001;20(1):152-7.

[24] Kazeem AO, Idowu OS, Olisamedua FN, Ayo S. Use of complementary and alternative medicine for children with chronic conditions in Lagos, Nigeria 2008: Available from: http// www.biomedcentral.com/1472-6882/8/66.

[25] Oshikoya KA, Njokanma OF, Bello JA, Ayorinde EO. The use of prescribed and nonprescribed drugs in infants in Lagos, Nigeria. $\mathbf{J}$ Med Sci. 2008;8:111-7.

[26] Oshikoya KA, Njokanma OF, Bello JA, Ayorinde EO. Family self-medication for children in an urban area of Nigeria. Paediatr Perinat Drug Ther. 2007;8:124-30.

[27] Breuner C, Barry P, Kemper K. Alternative Medicine Use by Homeless Youth. Arch Pediatr Adolesc Med. 1998;152:1071-5.

[28] Elder NC, Gillcrist A, Minz R. Use of Alternative Health Care by Family Practice Patients. Arch Fam Med. 1997;6(2):181-4.

[29] Singh V, Raidoo DM, Harris CS. The prevalence, pattern of usage and people's attitude towards complementary and alternative medicine (CAM) among the Indian community in Chatsworth, South Africa. BMC Complement Alternative Medicine. 2004;4:3.

[30] Fawole OI, Akinboye DO, Falade CO, Arulogun OS, Adeniyi JD. Case management of childhood fever by traditional healers in southwest Nigeria: identification of training and collaborative needs. International Quarterly of Community Health Education. 2007;28(4):319-35.

[31] Ayorinde F, Avery JW, Adekile AD, Ojewole JA, Odebiyi OO. Chemistry of a Nigerian Herbal Preparation (Cow's Urine Concoction) I. Journal of Tropical Pediatrics. 1982;28(5):235-9.

[32] Ezejiofor NA, Maduagwunan, Onyiaorah VI, Hussaini DC, Orisakwe OE. Multiple organ toxicity of a Nigerian herbal supplement (U \& D Sweet bitter) in male albino rats. Pak J Pharm Sci. 2008 Oct; 21(4):426-9.

[33] Ajaiyeoba EO, Oladepo O, Fawole OI, Bolaji OM, Akinboye DO, Ogundahunsi OA, et al. Cultural categorization of febrile illnesses in correlation with herbal remedies used for treatment in Southwestern Nigeria. J Ethnopharmacol. 2003;85(2-3):179-85.

[34] Unützer J, Klap R, Sturm R, Young AS, Marmon T, Shatkin J, et al. Mental Disorders and the Use of Alternative Medicine: Results From a National Survey. Am J Psychiatry. 2000;157:1851-7.

[35] Robinson A, Cooper S. Trusted Information Sources: The Preferred Option for Complementary and Alternative Medicine Users. Complementary Health Practice Review. 2007;12(2):120-38.

[36] Obi E, Akunyili DN, Ekpo B, Orisakwe OE. Heavy metal hazards of Nigerian herbal remedies. Sci Total Environ. 2006;369:35-41.

[37] Efuntoye M. Mycotoxins of fungal strains from stored herbal plants and mycotoxin contents of Nigerian crude herb drugs. Mycopathologica. 1999;147:43-8.

[38] Adeleye IA, Okogi G, Ojo EO. Microbial contamination of herbal preparations in Lagos, Nigeria. J Health Popul Nutr. 2005;23:296-7.

[39] Obi E, Agbasi PU, Ezejiofor NA, Maduagwuna C, Orisakwe OE. Safety warnings and first aid instructions on Nigerian traditional herbal remedies: are they adequate. World J Med Sci. 2006;1:108-11.

[40] Archer EL, Boyle DK. Herb and Supplement Use Among the Retail Population of an Independent, Urban Herb Store. J Holist Nurs. 2008;26(1):27-35.

[41] Esimone CO, Akah PA, Nworu CS. Efficacy and Safety Assessment of T. Angelica Herbal Tonic $®$, a Phytomedicinal Product Popularly Used in Nigeria. Evidence based Complementary and Alternative Medicine. 2009 September 13. 
Complementary and Alternative Medicine Use by the Indigenous Yoruba and Non-Indigenous Hausa People in Ibadan, Nigeria: A Qualitative Comparative Study

[42] Oyebola DDO. Care of the Neonate and Management of Neonatal Jaundice as Practised by Yoruba Traditional Healers of Nigeria. Journal of Tropical Pediatrics. 1983;29:18-22.
[43] Tasaki K, Maskarinec G, Shumay D, et al. Communication between physicians and cancer patients about complementary and alternative medicine: exploring patients' perspectives. Psychooncology. 2002;11:212-20.

Citation: Chinyerem C. Nwachukwu, et.al. Complementary and Alternative Medicine Use by the Indigenous Yoruba and Non-Indigenous Hausa People in Ibadan, Nigeria: A Qualitative Comparative Study. ARC Journal of Public Health and Community Medicine. 2021; 6(2):21-33. Doi:doi.org/10.20431/2456-0596.0602003.

Copyright: (C) 2021 Authors. This is an open-access article distributed under the terms of the Creative Commons Attribution License, which permits unrestricted use, distribution, and reproduction in any medium, provided the original author and source are credited. 